\title{
Angiotensin Converting Enzyme Gene Polymorphism as a Genetic Biomarker of Diabetic Peripheral Neuropathy: Longitudinal Prospective Study
}

\author{
J. Jurado', J. Ybarra² ${ }^{2 *}$ J.H. Romeo ${ }^{3}$, M. Garcia' and E. Zabaleta-del-Olmo ${ }^{4}$ \\ ${ }^{1}$ Institut d'Investigació en Atenció Primària Jordi Gol (IDIAP Jordi Gol), Olot, Girona, Spain \\ ${ }^{2}$ Clínica CIMA. Barcelona, Spain \\ ${ }^{3}$ Baldwin Wallace College. Berea, Ohio, USA \\ ${ }^{4}$ IDIAP Jordi Gol. Barcelona, Spain
}

\begin{abstract}
Background: Identifying patients at risk of developing diabetic peripheral neuropathy (DPN) is of paramount importance in those with type 2 diabetes mellitus (T2DM) to provide and anticipate secondary prevention measures as well as intensify action on risk factors, particularly so in primary care. Noteworthy, the incidence of DPN remains unknown in our environment.
\end{abstract}

Aims: i) to analyze Angiotensin Converting Enzyme (ACE) gene polymorphisms as a genetic marker of risk of developing DPN, ii) to determine the incidence of DPN in our environment.

Research design and methods: Longitudinal prospective cohort study with three years of follow-up involving a group of T2DM $(\mathrm{N}=283)$ randomly selected. ACE gene polymorphisms distribution (I=insertion; $\mathrm{D}=$ deletion) was determined. DPN was diagnosed using clinical and neurophysiology evaluation.

Results: Baseline DPN prevalence was 28.97\% (CI95\%:23.65-34.20), ACE polymorphism heterozygous genotype D/I presence was 60.77\% (CI95\%:55.05-66.5) and was independently associated with a decreased risk of DPN, RR: 0.51 (CI95\%, 0.30-0.86). DPN correlated with age $(\mathrm{p}<0.001)$ but not with gender $(\mathrm{p}=0.466)$ or time of evolution of T2DM ( $\mathrm{p}=0.555)$. End Point: DPN prevalence was $36.4 \%(\mathrm{CI} 95 \%, 30.76-42.04)$ and accumulated incidence was $10.4 \%$ three years thereafter. In the final Poisson regression analysis, the presence of heterozygous genotype remained independently associated with a decreased risk of DPN, RR 0.71 (CI95\%, 0.53-0.96). DPN presence remained correlated with age $(\mathrm{p}=0.002)$, but not with gender $(\mathrm{p}=0.490)$ or time of evolution $(\mathrm{p}=0.630)$.

Conclusions: In our series, heterozygous ACE polymorphism (D/I) stands as a protective factor for DPN development. Accumulated incidence of DPN was relevant. Further prospective studies are warranted.

Keywords: Type 2 diabetes mellitus (T2DM); Angiotensin converting enzyme (ACE); Gene polymorphism; Diabetic peripheral neuropathy (DPN)

\section{Introduction}

Diabetic peripheral neuropathy (DPN) is the most commonly reported long-term diabetic complication, affecting up to $20-40 \%$ of type 2 diabetic (T2DM) patients. Additionally, DPN is a major contributory factor in patients affected by diabetic foot ulceration and is being held responsible for up to 50-75\% of non-traumatic foot amputations [1]

Thus, taken into account its prevalence, its socioeconomic burden, the impact this has on quality of life, and on associated anxiety and depression, screening and appropriate treatment for DPN is of paramount importance [2].

The expected rise in T2DM prevalence will likely impose an increase in health care related costs. Simple and efficient methods are needed to detect the diabetic population at high risk of DPN. Thus, it is necessary to deploy significant efforts in clinical research focused on early detection of DPN. Particularly so, in primary care settings where preventive measures have proven efficient and efficacious in patient care as well as in the control of modifiable risk factors [3].

In practice, the diagnosis of DPN is usually employed to estimate the risk of foot ulceration. Thus preventive interventions are mainly aimed at avoidance of possible foot injuries. However, in addition to the metabolic control of diabetes [4], other risk factors of DPN susceptible of modification under preventive interventions have been identified. These include blood pressure control [5], lipid profile control [6], additional causes (neuro-toxic medications, vitamin B1, B6, B12 deficiencies and alcohol abuse) [7], interventions on lifestyle (exercise and diet) [8] and research into new therapies for treatment [9-11].

In addition to the proven association between metabolic control and complications of diabetes, there is a clear familial predisposition and likely link with genetic factors [12] expressed by the absence of complications in some patients with poor metabolic control.

*Corresponding author: Juan Ybarra, Clínica CIMA, Centro Médico Teknon, C/ Vilana 1208025 Barcelona, Spain, Tel: 0034933933 174; Fax: 0034933933074 E-mail: juanybarra@hotmail.com

Received November 01, 2011; Accepted November 21, 2011; Published November 30, 2011

Citation: Jurado J, Ybarra J, Romeo JH, Garcia M, Zabaleta-del-Olmo E (2011) Angiotensin Converting Enzyme Gene Polymorphism as a Genetic Biomarke of Diabetic Peripheral Neuropathy: Longitudinal Prospective Study. J Neurol Neurophysiol 2:121. doi:10.4172/2155-9562.1000121

Copyright: $\odot 2011$ Jurado J, et al. This is an open-access article distributed under the terms of the Creative Commons Attribution License, which permits unrestricted use, distribution, and reproduction in any medium, provided the original author and source are credited. 
Identification of potential candidates to develop DPN, particularly if performed prior to its clinical manifestations, would anticipate further secondary prevention measures and intensify action on risk factors. Furthermore, these measures would likely contribute to the reduction of morbidity and mortality and avoid the saturation of specialized services.

In this regard, in a previous study on the polymorphisms of angiotensin converting enzyme (ACE) gene [13] we observed that patients DPN expressed the heterozygous genotype frequency of " $\mathrm{D} / \mathrm{I}$ " less likely than patients without DPN. This findings suggested that the heterozygous genotype "D/I" could stand as putative protective factor against DPN development.

Moreover, we have not been able to find studies on the incidence of DPN in Spain while international studies are scarce. Some of them utilize diagnostic criteria which might underestimate $[4,14]$ or overestimate [15] the presence of DPN; while others employing appropriate criteria, show a cumulative incidence of $23.5 \%$ in seven years [5] in subjects with type 1 diabetes, with a different natural history of T2DM.

The aim of this study was to analyze the polymorphisms of ACE gene as a genetic marker of risk for DPN and determine the incidence of DPN in North Catalonia, Spain.

\section{Material and Methods}

\section{Research design and subjects}

A longitudinal prospective study at three years (2007-2010) was performed in a primary care setting in three different regions of North Catalonia (Spain).

Three hundred seven $(n=307)$ T2DM patients were initially selected, randomly recruited from the T2DM population proceeding from our cohorts of the North Catalonia Diabetes Study (NCDS) $[16,17]$. Selection criteria have been described extensively elsewhere $[16,17]$.

Inclusion criteria: T2DM patients diagnosed according to the World Health Organisation guidelines, aged between 35 and 75 years old.

Exclusion criteria: neuropathies of other aetiology, alcohol ingestion $>60 \mathrm{~g} /$ day in women and $\geq 80 \mathrm{~g} /$ day in men and refused consent.

All participants gave written informed consent to participate and the study was approved by the Primary Care Ethics Committee and the IDIAP Jordi Gol. The study was carried out in accordance with the principles of the declaration of Helsinki as revised in 2000 and 2008.

The dependent variables considered were the presence of DPN at baseline and its appearance upon follow-up. The independent variables were the ACE gene polymorphisms, gender, age, presence of cardiovascular disease and duration of T2DM (in years).

\section{Diabetic Peripheral Neuropathy (DPN)}

The patients were studied by a team of 28 health care providers including 16 nurse practitioners and 12 general practitioners. Study personnel underwent intensive training sessions totalling 24 hours. All examinations in each patient were performed by the same health care provider to control for inter-rater reliability.

Baseline results were obtained during 2007 and included age, time of T2DM evolution and cardiovascular disease (stroke, myocardial infarction, heart failure and peripheral vascular disease). The same team performed regular screenings to identify new cases of DPN as well as changes in the other baseline variables during the ensuing three years of follow-up (2008-2010). Diagnostic data were retrieved from case records and nerve conduction studies (NCS).

DPN diagnosis was based on clinical neurological examination (CNE) as well as the Neuropathy Symptoms Score being described previously [16,17], and NCS (by Synergy T-EPEMG/EP) in borderline subjects (i.e. those with dubious diagnosis). Nerve Conduction Studies (NCS) were performed in sural, median and ulnar nerves for upper extremities and in peroneal and tibial nerves for lower extremities (sensory and motor nerve conduction velocities), as described previously [16,17].

\section{Study of the ACE gene polymorphisms}

Samples were collected according to instructions in the manual of procedures routinely used in the extraction modules of Basic Health Areas. Blood samples were drawn from each subject after an overnight fast (10-12 h). DNA was extracted using the Puregene DNA purification Kit (Gentra Systems) following the manufacturer's specifications.

The angiotensin converting enzyme (ACE) gene has a diallelic polymorphism: presence (I) or absence (D) of $287 \mathrm{bp}$ in intron 16. DNA was subjected to amplification by PCR using an optimized primer pair (5'GCCCTGAGGTGTCTGCAGCATGT3' and 5'GGATGGCTCTCCCCGCCTTGTCTC3') that allowed the amplification of both alleles "D" and "I", resulting in 319-bp and 597-bp amplicons, respectively.

PCR reactions containing $0.8 \mu \mathrm{M}$ of each primer, $200 \mu \mathrm{M}$ dNTPs and $1 \mathrm{U}$ Taq DNA Polymerase (5 Prime GmbH, Deutschland) were subjected to 35 cycles consisting in denaturalization at $94^{\circ} \mathrm{C}$ for 30 seconds, annealing at $56^{\circ}$ for 45 seconds, and extension at $72^{\circ} \mathrm{C}$ for 2 minutes, in a Verities PCR (Applied Biosystems). Five $\mu$ l of each PCR were resolved in $2 \%$ agarose gels, and amplicons were visualized by ultraviolet transillumination.

Because the $\mathrm{D}$ allele in heterozygous samples is preferentially amplified, DD genotypes were subjected to a second PCR amplification with two insertion-specific primers for allele I, in order to confirm its absence: 5'TGGGACCACAGCGCCCGCCACTAC3' and 5'TCGCCAGCCCTCCCATGCCCATAA3'. PCR conditions were identical except for an annealing temperature of $72^{\circ} \mathrm{C}$.

\section{Sample size}

The Poisson approximation was used to calculate sample size Accepting an alpha risk of 0.05 and a beta risk of less than 0.2 in a bilateral contrast, 238 subjects were needed to detect a minimum relative risk of 2.14 [14] if the rate of DPN in the unexposed group is 0.15 . It has been estimated a loss rate up to $10 \%$, taking into account a previous study [13] and the prevalence of DPN observed our cohorts $[16,17]$.

\section{Statistical analysis}

Proportions between groups were compared with the chi-square test. Continuous variables were expressed as mean and standard deviation (SD) and were compared by Student's t-test.

Covariates that were of known clinical interest or that were identified as significant $(\mathrm{p}<0.05)$ in the bivariate analyses were selected for multivariate analyses, which was performed employing Poisson regression models for analyzing the association between the genotype 
and DPN. We fitted all models in a customized way by means of the ENTER method. Results were expressed as relative risks with the corresponding robust $95 \%$ confidence intervals $(\mathrm{CI})$.

The level of statistical significance was established as $\mathrm{p}<0.05$.

All analyses were performed with the STATA v.9 statistical package.

\section{Results}

Of the three hundred and seven $(\mathrm{N}=307)$ patients initially selected, twenty-four ( $\mathrm{n}=24 ; 7.81 \%)$ did not sign informed consent or were lost before the first year of follow-up.

Finally, two-hundred and eighty-three $(n=283)$ T2DM patients were included in the study. There were no significant differences in age and gender between the initially selected group and the remaining cohort included in the study (data not shown). Table 1 provides the baseline characteristics of the participants.

As shown, 201 patients had no diabetic polyneuropathy (DPN) at the time of inclusion whereas 82 patients had DPN (28.97\%). No patients were lost after the first year of follow-up.

As shown, participants were in their sixties and men outnumbered women, as in our population with T2DM.

DPN presence was positively related with age $(\mathrm{P}<0.001)$, age $>$ 65 y.o. $(\mathrm{P}<0.001)$, and negatively related with heterozygous $(\mathrm{D} / \mathrm{I})$ polymorphism $(\mathrm{p}=0.011)$ but not with gender $(\mathrm{p}=0.466)$ or time of T2DM evolution (years; $\mathrm{P}=0.555$ ) at the beginning of the study. Age, cardiovascular disease and the presence of the heterozygous (D/I) polymorphism were associated in the bivariate analysis with DPN during follow-up (Table 2).

In the final Poisson regression analysis, age and the presence of CVD remained independently associated with an increased risk of DPN whereas the presence of heterozygous genotype (D/I), remained independently associated with a decreased risk of DPN (Table 3).

Gender and time of T2DM evolution did not disclose significant relative risks of DPN from baseline till the end of the study. Contrarily, age disclosed a significant and consistent relative risk of developing DPN from baseline and year-after-year, till the end of the study (Table 4).

Heterozygous (D/I) ACE gene polymorphism disclosed a statistically significant reduced relative risk of developing DPN from the beginning of the study and year-by-year till the end of follow-up (Table 4).

Homozygous (D/D) ACE gene polymorphism disclosed an

\begin{tabular}{|l|c|}
\hline N (Gender) & $283(175$ males $/ 108$ females $)$ \\
\hline Women & $38.16(32.50-43.81)$ \\
\hline Caucasian & $100 \%$ \\
\hline Age $^{*}$ & $63.58(7.72)$ \\
\hline Age $>65 y$ & $44.52(38.70-50.35)$ \\
\hline History of CVD & $19.78(15.11-24.45)$ \\
\hline History of DPN & $28.97(23.65-34.29)$ \\
\hline Heterozygous & $60.77(55.05-66.50)$ \\
\hline T2DM evolution (years) $^{*}$ & $6.19(3.47)$ \\
\hline
\end{tabular}

Table 1: Baseline characteristics of the participants. CVD: cardio-vascular disease DPN: diabetic peripheral neuropathy. Values are percentages $(95 \% \mathrm{Cl})$ unless stated otherwise. *: mean (SD).

\begin{tabular}{|c|c|c|c|}
\hline \multirow[t]{2}{*}{ Factors } & \multicolumn{2}{|c|}{ Diabetic Polyneuropathy } & \multirow[t]{2}{*}{ P-value } \\
\hline & Yes & No & \\
\hline Women & 40.78 & 36.67 & 0.493 \\
\hline Age $^{*}$ & $69.85(6.39)$ & $65.98(8.25)$ & $<0.001$ \\
\hline Age $>65 y$ & 76.70 & 55.00 & $<0.001$ \\
\hline CVD & 56.31 & 37.22 & 0.002 \\
\hline Heterozygous (D/I) & 52.42 & 65.55 & 0.032 \\
\hline T2DM evolution (years) ${ }^{*}$ & $10.15(3.55)$ & $9.93(3.71)$ & 0.639 \\
\hline
\end{tabular}

Table 2: Factors associated with total Diabetic Polyneuropathy (DPN) events at three-year follow-up. Values are percentages $(95 \% \mathrm{Cl})$ unless stated otherwise. *Mean (SD) DPN: diabetic peripheral neuropathy, CVD: cardiovascular disease.

\begin{tabular}{|l|c|c|}
\hline \multicolumn{1}{|c|}{ Factors } & RR $(\mathbf{9 5 \%} \mathbf{C l})$ & P-value \\
\hline Women & $1.12(0.83-1.52)$ & 0.44 \\
\hline Age $>65 y$ & $1.46(1.05-2.03)$ & 0.02 \\
\hline Heterozygous & $0.71(0.53-0.96)$ & 0.02 \\
\hline CVD & $1.48(1.06-2.05)$ & 0.01 \\
\hline \multicolumn{2}{|l|}{ Godness-of-fit (Hosmer-Lemeshow $\left.\mathrm{X}^{2}\right) \mathrm{p}=0.82}$. \\
\hline
\end{tabular}

Table 3: Poisson regression model of total DPN events at three-year follow-up. CVD.

increased relative risk of developing DPN at baseline whose initial significance was lost thereafter. Noteworthy, the initial increase in relative risk was reversed to a decrease in relative risk from year one of follow-up and so on; nevertheless, this decreased relative risk did not attain statistical significance (Table 4).

DPN's observed annual incidence was 3.88\% (CI95\%: 1.25-6.70) during the first year of follow-up (8/201 patients), 3.11\% (CI95\%: 0.64 5.57) during the second year of follow-up (6/193 patients) and $3.74 \%$ (CI95\%: 0.99-6.48) during the third year of follow-up (7/187 patients). At the end of the study (third year) DPN's incidence was $10.44 \%$ (CI95\%: 6.18-14.71) (data not shown).

\section{Discussion}

The current longitudinal prospective cohort pilot study was set forth to analyze ACE gene polymorphisms as a genetic risk marker of developing DPN and to determine the incidence of DPN in our environment (North Catalonia, Spain). The most novel finding of our study is the protective effect of a heterozygous (D/I) ACE gene polymorphism on the development of DPN. Hence, our results show that, at the beginning, throughout and at the end of the study, the presence of DPN was negatively related to the heterozygous (D/I) genotype. Despite ACE gene polymorphisms association with diabetic renal disease and/or diabetic retinopathy [7,17-19], its relationship with DPN was not clear, therefore the present study establishes a precedent since, to the best of our knowledge this finding had not been reported previously.

The results confirm those obtained in a previous study of our group [13] on ACE gene polymorphisms in T2DM patients with cardiovascular disease when we observed that those patients disclosing DPN presented the heterozygous (D/I) genotype less frequently than those without DPN while homozygous genotypes (D/D and I/I) appeared with similar frequencies in patients with or without DPN. These results suggested, rather surprisingly, that the heterozygous genotype $(\mathrm{D} / \mathrm{I})$ could stand as a protective factor against the presence of DPN.

This significant presence of heterozygous combinations, but related to other genes, has also been observed associated with a reduced prevalence of neuropathy in T2DM [20]. 
While the relationship between the DPN and the aldose reductase gene [21] is well documented, we found scant literature on its possible relation to the ACE gene polymorphisms. Ito et al. reported that the "I" allele frequency was significantly higher in patients with DPN without macroalbuminuria [22]. Stephens et al. [23] reported the presence of the "D" allele being associated with an increase risk of DPN in women and Costacou et al. [14] described the "D/D" genotype as a risk factor for DPN. Interestingly, in our series, homozygous (D/D) ACE gene polymorphism disclosed an increased relative risk of developing DPN at baseline whose initial significance was lost thereafter. Noteworthy, the initial increase relative risk was reversed to a decreased relative risk from year one of follow-up and so on; nevertheless, this decreased relative risk did not attain statistical significance although a trend appeared from the first year till the end of the study (Table 4).

Suzuki et al. [24] reported inactivity and/or dominance of the $\mathrm{ALDH} 2 / \mathrm{ADH} 2$ polymorphism in relation to DPN's presence.

Regarding the polymorphisms study the main drawback of our study is that we only studied the ACE gene, taking into account that DPN is likely a multifactorial micro-angiopathic complication with a polygenic background. Thus, our methodology does not allow an analysis of association and high density single nucleotide polymorphisms (SNP) maps.

Furthermore, DPN presence correlated positively with age as reported previously $[5,17,19]$. Contrarily, DPN presence was not related to either gender or time of evolution of T2DM (Table 4). The lack of correlation between DPN presence and time of diabetes evolution falls in contradiction with previous reports $[5,17,19]$ but, noteworthy, in agreement with Sands et al. in T2DM [15]. One likely explanation might be that the onset of DPN in T2DM is often insidious and more subtle than in Type-1 diabetics and, more often than not, T2DM patients's diagnosis is delayed by several years. Moreover the natural history of both types of diabetes is different.

In Spain, during the period 2001-2008, the rate of non-traumatic amputations in T2DM patients, instead of diminishing, has increased $[25,26]$, indicating the urgency of caring for and preventing foot injuries. The evidence shows that it is possible to reduce the number of amputations [27-29], by means of a correct Diabetes Service organization and the control of different risk factors [4-8].

DPN stands in a prominent position among the risk factors for amputation and also in itself as a cause of suffering and expense $[1,2]$. Despite the fact of being investigated by several new therapeutic modalities [9-11,30-32], the recognition of the difficulty in reversing established DPN has focused efforts at slowing DPN's progression [33].
Early diagnosis of DPN [34] and the detection of innovative risk markers [35-39] allow anticipating preventive care. Among these risk and/or protective factors, related genetic [12-14,18,21-24,40-43] and epigenetic factors [44] are probably the ones most likely to enable the maximum advance.

The determination of the ACE gene polymorphisms poses economic and availability problems to make its determinations similar to those raised in his day by the HbAlc and the islet-cell antibodies determination as well as other procedures that are common today in practice.

In the short term biotechnology will provide microarrays and biochips for detection of SNPs with low-cost services; then genetic testing will likely become an integral part of health care.

The future of genetics in public health will likely include the development of genetic testing, prevention services and health promotion, evaluation and monitoring of individuals and families at risk, genetic counseling and professional training in genetics, all within the context primary of care settings.

The second aim of our study was to determine the incidence of DPN in our environment. As shown, the cumulative incidence of DPN at three years was slightly higher than that observed in subjects with type 1 diabetes [5]. To study the incidence of DPN, monitoring was limited to three years, but by design and size, the study has adequate power and statistical significance.

The design of the study is not flawed by information, monitoring or selection bias, since drop-outs were less than $7.5 \%$ and the resulting sample showed no significant age or gender differences with the randomly selected cohort. Noteworthy, it is representative of our general population with T2DM.

The assessment of DPN's incidence is difficult, among other reasons due to the lack of unified diagnostic criteria, the low sensitivity to detect subtle forms of DPN and few cohort studies. In Spain we have not seen studies on the incidence of DPN in type 2 diabetic patients, so this study also sets a precedent in this regard.

Internationally, few studies cite the incidence of DPN in T2DM. Both the UKPDS [4] (using a biotensiometer $\geq 25$ volts) as well as the paper by Costacou [14] used diagnostic criteria which, we believe underestimate the presence of DPN in T2DM. Otherwise, Sands [15] used diagnostic criteria which, we believe overestimate the presence of DPN in T2DM. The study by Tesfaye [5], which we believe utilized the most appropriate criteria for DPN's diagnosis, found a cumulative

\begin{tabular}{|c|c|c|c|c|c|c|c|c|}
\hline \multirow{3}{*}{ Variable } & \multicolumn{8}{|c|}{ FOLLOW-UP } \\
\hline & \multicolumn{2}{|l|}{ Base line } & \multicolumn{2}{|c|}{ One year follow } & \multicolumn{2}{|c|}{ Two years follow } & \multicolumn{2}{|c|}{ Three years follow } \\
\hline & $\mathrm{RR}$ & $P$ & RR & $\mathrm{P}$ & RR & $P$ & RR & $\mathrm{P}$ \\
\hline Gender & $0.823(0.487-1.390)$ & 0.466 & $1.200(0.719-2.001)$ & 0.486 & $1.250(0.756-2.068)$ & 0.385 & $1.189(0.724-1.954)$ & 0.494 \\
\hline Age (years) & $1.086(1.043-1.131)$ & $<0.001$ & $1.073(1.034-1.114)$ & $<0.001$ & $1.073(1.035-1.113)$ & $<0.001$ & $1.073(1.036-1.112)$ & $<0.001$ \\
\hline T2DM Evolution (y) & $0.978(0.908-1.053)$ & 0.555 & $0.990(0.921-1.060)$ & 0.772 & $1.017(0.950-1.088)$ & 0.630 & $1.016(0.951-1.086)$ & 0.637 \\
\hline Heterozygous (D/I) & $0.509(0.302-0.857)$ & 0.011 & $0.569(0.342-0.945)$ & 0.029 & $0.555(0.337-0.916)$ & 0.021 & $0.557(0.340-0.913)$ & 0.020 \\
\hline Homozygous (D/D) & $1.742(1.004-3.025)$ & 0.048 & $0.648(0.377-1.114)$ & 0.116 & $0.595(0.349-1.015)$ & 0.057 & $0.602(0.355-1.022)$ & 0.060 \\
\hline Homozygous (I/I) & $1.402(0.639-3.075)$ & 0.399 & $1.409(0.652-3.044)$ & 0.383 & $1.263(0.568-2.725)$ & 0.551 & $1.300(0.609-2.776)$ & 0.498 \\
\hline
\end{tabular}

Table 4: Variables related with DPN presence during follow-up. RR: Relative Risk, Cl: confidence interval. 
Citation: Jurado J, Ybarra J, Romeo JH, Garcia M, Zabaleta-del-Olmo E (2011) Angiotensin Converting Enzyme Gene Polymorphism as a Genetic Biomarker of Diabetic Peripheral Neuropathy: Longitudinal Prospective Study. J Neurol Neurophysiol 2:121. doi:10.4172/2155-9562.1000121

incidence of 23.5 percent in seven years for patients with type 1 diabetes. In our study we observed a slightly higher incidence, probably due to the special characteristics of the natural history of TDM2.

In our series, DPN's categorical not development can be significant and independently predicted by $\mathrm{D} / \mathrm{I}$ allele of ACE gen polymorphisms and age. Accordingly, D/I allele ACE gene polymorphisms appears as a key effector protector, displaying significant independent correlations with diabetic neuropathy absence. Therefore, it could be used as a novel gene marker for diabetic peripheral neuropathy risk development. Further prospective studies are warranted.

\section{Acknowledgements}

The authors wish to express their acknowledgment to the members of the research team: Teresa Barnera, Paquita Bataller, Rocio Blanco, Natalia Brossa Anna Dorca, Marta Duran, Maria Ferrandiz, Loreto Noguer, Roser Rifà and Pepa Sardañes (Catalan Institute of Health), Girona, Spain.

This work was supported by a grant from Fondo de Investigación Sanitaria: FIS PI070340, Instituto Carlos III of Spain. Plan Nacional I+D+i 2008-2010 and FEDER.

\section{References}

1. Holzer SE, Camerota A, Martens L, Cuerdon T, Crystal-Peters J, et al. (1998) Costs and duration of care for lower extremity ulcers in patients with diabetes. Clin Ther 20: 169-181.

2. Mayfield JA, Reiber GE, Sanders LJ, Janisse D, Pogach LM (1998) Preventive Foot Care in People With Diabetes. Diabetes Care 21: 2161-2177.

3. Boulton AJ, Vileikyte $L$ (2000) The diabetic foot: the scope of the problem. J Fam Pract 49: S3-S8.

4. (1998) UK Prospective Diabetes Study Group. Intensive blood-glucose control with sulphonylureas or insulin compared with conventional treatment and risk of complications in patients with type 2 diabetes (UKPDS 33). Lancet 352: 837 853.

5. Tesfaye S, Chaturvedi N, Eaton SE, Ward JD, Manes C, et al (2005) Vascular Risk Factors and Diabetic Neuropathy. N Engl J Med 352: 341-350.

6. Vinik Al, Erbas T, Park TS, Stansberry KB, Scanelli JA, et al. (2001) Dermal Neurovascular Dysfunction in Type 2 Diabetes. Diabetes Care 24: 1468-1475.

7. Gorson KC, Ropper AH (2006) Addicional causes for distal sensory polyneuropathy in diabetic patients. J Neurol Neurosurg Psichiatry 77: 354-358.

8. Smith AG, Russell J, Feldman EL, Goldstein J, Peltier A, et al. (2006) Lifestyle intervention for pre-diabetic neuropathy. Diabetes Care 29: 1294-1299.

9. Price SA, Dent C, Duran-Jimenez B, Liang Y, Zhang L, et al. (2006) Gene Transfer of an Engineered Transcription Factor Promoting Expression of VEGF-A Protects Against Experimental Diabetic Neuropathy. Diabetes 55: 1847-1854.

10. Schemmel KE, Padiyara RS, D'Souza JJ (2010) Aldose reductase inhibitors in the treatment of diabetic peripheral neuropathy: a review. J Diabetes Complications 24: 354-360.

11. Volarevic V, Arsenijevic N, Lukic ML, Stojkovic M (2010) Mesenchymal Stem Cell Treatment of Complications of Diabetes Mellitus. Stem Cells 2010.

12. Burdon KP, Langefeld CD, Wagenknecht LE, Carr JJ, Freedman BI, et al. (2006) Association analysis of genes in the reninangiotensin system with subclinical cardiovascular disease in families with Type 2 diabetes mellitus: the Diabetes Heart Study. Diabet Med 23: 228-234.

13. Jurado J, Pastoret M, Ybarra J, Gich I, Pou JM, et al. (2006) Cardiovascular Disease, Diabetic Polyneuropathy and ACE gene polymorphisms in the North Catalonia Diabetes Study (NCDS). Diabetologia 21: 140-148.

14. Costacou T, Chang Y, Ferrell RE, Orchard TJ (2006) Identifying Genetic Susceptibilities to Diabetes-related Complications among Individuals at Low Risk of Complications: An Application of Tree-Structured Survival Analysis. Am J Epidemiol 164: 862-872.
15. Sands ML, Shetterly SM, Franklin GM, Hamman RF (1977) Incidence of distal symmetric (sensory) neuropathy in NIDDM. The San Luis Valley Diabetes Study. Diabetes Care 20: 322-329.

16. Jurado J, Caula J, Pou JM (2006) [Selection of risk and diagnosis in diabetic polyneuropathy. Validation of method of new systems]. Aten Primaria 30: 116121.

17. Jurado J, Ybarra J, Romeo JH, Pou JM (2009) Clinical Screening and Diagnosis of Diabetic Polyneuropathy: The North Catalonia Diabetes Study. Eur J Clin Invest 39: 183-189.

18. Klemm T, Paschke R (2000) [Possible genetic causes for late complications of diabetes mellitus]. Med Klin (Munich) 95: 31-39.

19. Tapp RJ, Shaw JE, De Courten MP, Dunstan DW, Welborn TA, et al. (2003) Foot complications in type 2 diabetes: an Australian population-based study. Diabet Med 20: 105-113.

20. Rudofsky G Jr, Reismann P, Witte S, Humpert PM, Isermann B, et al. (2004) Asp299Gly and Thr399lle genotypes of the TLR4 gene are associated with a reduced prevalence of diabetic neuropathy in patients with type 2 diabetes. Diabetes Care 27: 179-183

21. Sivenius K, Pihlajamaki J, Partanen J, Niskanen L, Laakso M, et al. (2004) Aldose reductase gene polymorphisms and peripheral nerve function in patients with type 2 diabetes. Diabetes Care 27: 2021-2026.

22. Ito H, Tsukui S, Kanda T, Utsugi T, Ohno T, et al. (2003) Angiotensin-converting enzyme insertion/delection polymorphism and polyneuropathy in type 2 diabetes without macroalbuminuria. J Int Med Res 30: 476-482.

23. Stephens JW, Dhamrait SS, Acharya J, Humphries SE, Hurel SJ (2006) A common variant in the ACE gene is associated with peripheral neuropathy in women with type 2 diabetes mellitus. J Diabetes Complications 20: 317-321.

24. Suzuki Y, Taniyama M, Muramatsu T, Higuchi S, Ohta S, et al. (2004) ALDH2/ $\mathrm{ADH} 2$ polymorphism associated with vasculopathy and neuropathy in type 2 diabetes. Alcohol Clin Exp Res 28: 111S-116S.

25. http://www.oecd-ilibrary.org/avoidable-admissions-diabetes complications_5ks5mgftfbzw.pdf?contentType=/ns/Chapter,/ns/ StatisticalPublication\&item Id=/content/chapter/health_glance-2009-49en\&containerltemld=/content/serial/ 19991312\&accessltemlds=\&mimeType= application/pdf

26. López-de-Andrés A, Martínez-Huedo MA, Carrasco-Garrido $P$, Hernández Barrera V, Gil-de-Miguel A,et al. (2011) Trends in Lower-Extremity Amputations in People With and Without Diabetes in Spain, 2001-2008. Diabetes Care 34: $1570-1576$.

27. Vamos EP, Bottle A, Edmonds ME, Valabhji J, Majeed A,et al. (2010) Changes in the incidence of lower extremity amputations in individuals with and withou diabetes in England between 2004 and 2008. Diabetes Care 33: 2592-2597.

28. Yesil S, Akinci B, Bayraktar F, Havitcioglu H, Karabay O, et al. (2009) Reduction of major amputations after starting a multidisciplinary diabetic foot care team: single centre experience from Turkey. Exp Clin Endocrinol Diabetes 117 345-349.

29. Ikonen TS, Sund R, Venermo M, Winell K (2010) Fewer major amputations among individuals with diabetes in Finland in 1997-2007: a population-based study. Diabetes Care 33: 2598-2603.

30. Kamiya H, Zhang W, Sima AA (2009) The beneficial effects of C-Peptide on diabetic polyneuropathy. Rev Diabet Stud 6: 187-202.

31. Ropper AH, Gorson KC, Gooch CL, Weinberg DH, Pieczek A, et al. (2009) Vascular endothelial growth factor gene transfer for diabetic polyneuropathy: a randomized, double-blinded trial. Ann Neurol 65: 386-393.

32. Obrosova IG, Stavniichuk R, Drel VR, Shevalye H, Vareniuk I, et al. (2010) Different roles of 12/15-lipoxygenase in diabetic large and small fiber periphera and autonomic neuropathies. Am J Pathol 177: 1436-1447.

33. Tahrani AA, Askwith T, Stevens MJ (2010) Emerging drugs for diabetic neuropathy. Expert Opin Emerg Drugs 15: 661-683.

34. Tesfaye S, Boulton AJ, Dyck PJ, Freeman R, Horowitz M, et al. (2010) Toronto Diabetic Neuropathy Expert Group. Diabetic neuropathies: update on defini- 
Citation: Jurado J, Ybarra J, Romeo JH, Garcia M, Zabaleta-del-Olmo E (2011) Angiotensin Converting Enzyme Gene Polymorphism as a Genetic Biomarker of Diabetic Peripheral Neuropathy: Longitudinal Prospective Study. J Neurol Neurophysiol 2:121. doi:10.4172/2155-9562.1000121

Page 6 of 6

tions, diagnostic criteria, estimation of severity, and treatments. Diabetes Care 33: $2285-2293$

35. Cho HC (2010) The Association between Serum GGT Concentration and Diabetic Peripheral Polyneuropathy in Type 2 Diabetic Patients. Korean Diabetes J 34: 111-118.

36. Kolla VK, Madhavi G, Pulla Reddy B, Srikanth Babu BM, et al. (2009) Association of tumor necrosis factor alpha, interferon gamma and interleukin 10 gene polymorphisms with peripheral neuropathy in South Indian patients with type 2 diabetes. Cytokine 47: 173-177

37. Cermenati G, Giatti S, Cavaletti G, Bianchi R, Maschi O, et al. (2010) Activation of the liver $X$ receptor increases neuroactive steroid levels and protects from diabetes-induced peripheral neuropathy. J Neurosci 30: 11896-11901.

38. Ybarra J, Pou JM, Romeo JH, Mercé J, Jurado J (2010) Transforming Growth Factor 1 (TGFB1) as a biomarker of Diabetic Peripheral Neuropathy: Crosssectional Study. J Diabetes Complications 24: 306-312.

39. Wu Z, Mata M, Fink DJ (2011) Prevention of diabetic neuropathy by regulatable expression of HSV-mediated erythropoietin. Mol Ther 19: 310-317.
40. Papanas N, Papatheodorou K, Papazoglou D, Kotsiou S, Christakidis D, et al. (2007) An insertion/deletion polymorphism in the alpha2B adrenoceptor gene is associated with peripheral neuropathy in patients with type 2 diabetes mellitus. Exp Clin Endocrinol Diabetes 115: 327-330.

41. Lee G, Xiang Z, Brannagan TH 3rd, Chin RL, Latov N (2010) Differential gene expression in chronic inflammatory demyelinating polyneuropathy (CIDP) skin biopsies. J Neurol Sci 290: 115-122.

42. Yamasaki H, Sasaki H, Ogawa K, Shono T, Tamura S, et al. (2006) Uncoupling protein 2 promoter polymorphism -866G/A affects peripheral nerve dysfunction in Japanese type 2 diabetic patients. Diabetes Care 29: 888-894.

43. Tian C, Fang S, Du X, Jia C (2011) Association of the C47T polymorphism in SOD2 with diabetes mellitus and diabetic microvascular complications: a metaanalysis. Diabetologia 54: 803-811.

44. Gaikwad AB, Gupta J, Tikoo K (2010) Epigenetic changes and alteration of Fbn1 and Col3A1 gene expression under hyperglycaemic and hyperinsulinaemic conditions. Biochem J 432: 333-341. 